Annales Geophysicae (2004) 22: 2135-2149

SRef-ID: $1432-0576 / \mathrm{ag} / 2004-22-2135$

(C) European Geosciences Union 2004

\title{
Substorm behavior of the auroral electrojet indices
}

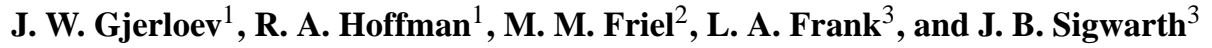 \\ ${ }^{1}$ Applied Physics Laboratory, Johns Hopkins University, 11100 Johns Hopkins Road, Laurel, MD 20723, USA \\ ${ }^{2}$ SP Systems, 7501 Forbes Blvd., Suite 206, Seabrook, MD. 20706-2253, USA \\ ${ }^{3}$ Department of Physics and Astronomy, University of Iowa, Iowa City, IA 52242, USA
}

Received: 18 July 2003 - Revised: 12 January 2004 - Accepted: 28 January 2004 - Published: 14 June 2004

\begin{abstract}
The behavior of the auroral electrojet indices AU and AL during classical substorms is investigated by the use of global auroral images. A superposition of the $12 \mathrm{AE}$ stations onto global auroral images and identification of the $\mathrm{AL}$ and $\mathrm{AU}$ contributing stations enable an understanding of the temporal as well as spatial behavior of the indices with respect to the substorm coordinate system and timeframe. Based on this simple technique it was found that at substorm onset the AL contributing station makes a characteristic jump from a location near the dawn terminator to the onset region, typically bypassing one or more AE stations. During the expansion phase this station typically lies at the poleward edge of the surge region. This is the location of the intense substorm current wedge electrojet in the semiempirical self-consistent substorm model of the three-dimensional current system by Gjerloev and Hoffman (2002). This current wedge is fed primarily pre-midnight by an imbalance of the Region 0 and Region 1 field-aligned currents, not from the dawnside westward electrojet. Then during the early recovery phase the AL contributing station jumps back to the dawn sector. The defining AU station does not show any similar systematic behavior. We also find that the dawn side westward electrojet seems to be unaffected by the introduction of the substorm current wedge. According to our model, much of this current is closed to the magnetosphere as it approaches midnight from dawn. Based on the characteristics of the AL station jumps, the behavior of the dawn-side electrojet, and the understanding of the three-dimensional substorm current system from our model, we provide additional experimental evidence for, and an understanding of, the concept of the two component westward electrojet, as suggested by Kamide and Kokubun (1996).
\end{abstract}

Key words. Magnetospheric physics (current systems; auroral phenomena; storms and substorms)

Correspondence to: J. W. Gjerloev

(jesper.gjerloev@jhuapl.edu)

\section{Introduction}

The auroral electrojet indices AL and AU from which AE is calculated have been used extensively since they were introduced by Davis and Sugiura (1966). Historically, the indices have been interpreted as a monitor of the auroral electrojet activity and thereby of magnetospheric activity. Thus, the indices have been found useful in various statistical studies for data selection as well as organization.

Due to the popularity of the indices the limitations and interpretations have naturally become an important issue (e.g. UT effects, Rostoker, 1972; Allen and Kroehl, 1975; Ahn et al., 2000, 2002). The limitations are primarily due to the small number of magnetometer stations used (10-12 stations) and their uneven spatial distribution (see Fig. 1 and Table 1 for their locations), thereby implying that large perturbations can go undetected if they are constrained in longitude or are located at latitudes poleward or equatorward of the AE station network. Davis and Sugiura (1966) noted that the network of AE stations with wide geomagnetic longitudinal gaps (with an average of $30^{\circ}$ and up to $\sim 48.2^{\circ}$ between Tixie Bay and Cape Wellen) was inadequate in monitoring the auroral electrojet system. Rostoker (1972) addressed the effect of the equatorward expansion of the auroral electrojets on the index and concluded that, in order to avoid the obvious pitfalls of the index, it should be used only in statistical studies rather than individual events.

The basic limitation to the AL and AU indices is the fact that they are one-dimensional scalars, which simply indicates the maximum perturbation measured at one of the AE station locations. Hence, they are local indices and are not a measure of the global electrojet activity, although it is often found in the literature that the global electrojet configuration is presumptuously deduced. Acknowledging this obvious problem Allen and Kroehl (1975) and later Kamide (1982) used a different approach. Rather than treating the indices as a simple time series they included the available knowledge of the location of the contributing stations. The AU and AL indices are defined as the upper and lower envelopes of the 
Table 1. Geographic coordinates and corrected geomagnetic coordinates for the 12 AE stations.

\begin{tabular}{lccccc}
\hline Observatory & IAGA Code & $\begin{array}{c}\text { Geographic } \\
\text { Latitude }\end{array}$ & $\begin{array}{c}\text { Geographic } \\
\text { Longitude }\end{array}$ & $\begin{array}{c}\text { CGM } \\
\text { Latitude }\end{array}$ & $\begin{array}{c}\text { CGM } \\
\text { Longitude }\end{array}$ \\
\hline Abisko & ABK & 68.36 & 18.82 & 65.11 & 102.30 \\
Dixon Island & DIK & 73.55 & 80.57 & 68.39 & 156.01 \\
Cape Chelyuskin & CCS & 77.72 & 104.28 & 71.75 & 175.55 \\
Tixie Bay & TIK & 71.58 & 129.00 & 65.75 & 197.06 \\
Cape Wellen & CWE & 66.17 & 190.17 & 62.85 & 245.22 \\
Barrow & BRW & 71.30 & 203.25 & 70.03 & 250.02 \\
College & CMO & 64.87 & 212.17 & 65.12 & 263.05 \\
Yellowknife & YKC & 62.40 & 245.60 & 69.70 & 299.42 \\
Fort Churchill & FCC & 58.80 & 265.90 & 69.28 & 331.39 \\
Great Whale River & GWC & 55.27 & 282.22 & 66.13 & 358.40 \\
Narssarssuaq & NAQ & 61.20 & 314.16 & 66.47 & 43.91 \\
Leirvogur & LRV & 64.18 & 338.30 & 65.10 & 67.82 \\
\hline
\end{tabular}

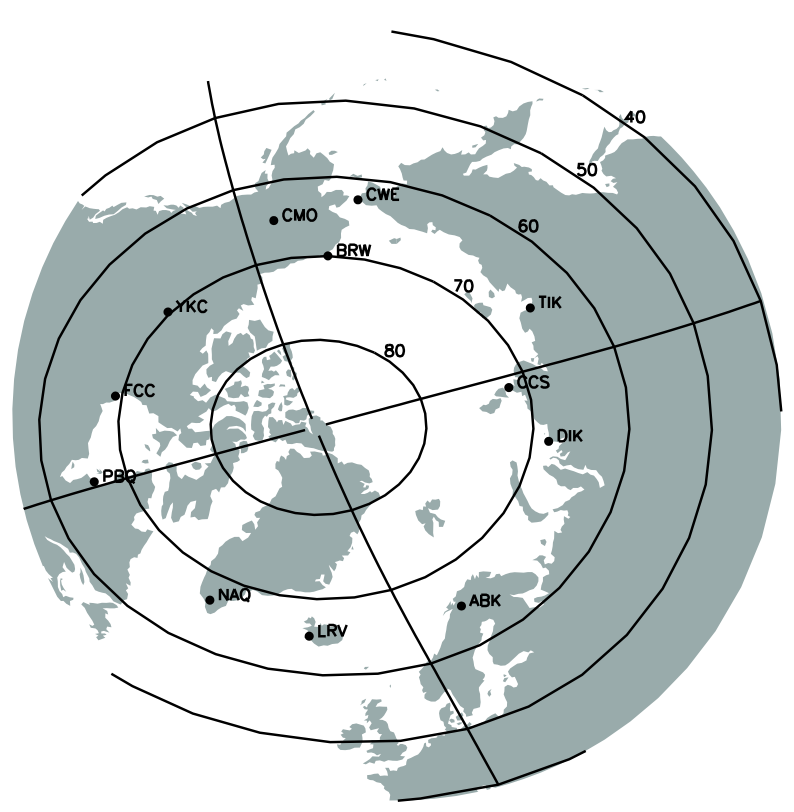

Fig. 1. Spatial distribution of AE-stations with corrected geomagnetic coordinates and continents.

10-12 AE ground-based magnetometer station's measured $\mathrm{H}$-perturbation. Hence, at a given time the value of AL is defined by only one station, what we refer to as the contributing station. Allen and Kroehl (1975) found that during disturbed times (simply defined as $\mathrm{AL} \leq-50 \mathrm{nT}$ ), AL was most often derived from stations located post-midnight at $\sim 03: 00$ MLT. Kamide (1982) identified 1360 substorms and found that for $57 \%$ of the substorms the AL station was located at local times earlier than 03:00 MLT at the time of the AL minimum, after which it moved to 03:00-09:00 MLT.

Kamide (1982) also examined the characteristics of the longitudinal center of the substorm westward electrojet in more detail, using the AL index, as well as some of the IMS meridian chain records. He found that in $57 \%$ of the sub- storms the AL defining station made an eastward shift from the 15:00-03:00 MLT sector (during minimum $\mathrm{AL} \pm 15 \mathrm{~min}$ ) to the morning sector 03:00-09:00 MLT (after AL minimum $+15 \mathrm{~min}$ ).

In no study to date has the relationship of the location of the defining station to the temporal evolution or morphology of the optical auroral substorm been investigated, nor has much attention been given to the behavior of the AU index during substorms. To obtain these relationships and behaviors we use a new approach, superimposing the AL and AU stations on global auroral images during classical bulge-type auroral substorms. With this technique we determine the location of the defining $\mathrm{AL}$ and $\mathrm{AU}$ stations with respect to the auroral substorm morphology and more accurately, the magnetic local time of the defining stations as a function of substorm phase. We also add another dimension to the analysis, the latitude of the defining station relative to the auroral morphology, not possible in previous studies. From this analysis and from the results of our previously published selfconsistent substorm model (Gjerloev and Hoffman, 2002), we can gain insights into when and where the AL station shifts occur during substorms and where the AU station resides.

Section 2 of this paper describes the approach to our analysis. Section 3 shows four examples of substorms to illustrate the various types of behavior of the indices. Section 4 provides an overview analysis of the 34 substorms used in the study; and Sect. 5 is a discussion of the results and an interpretation of the AL-AU behavior based on the previously published concepts.

\section{Approach}

Final auroral electrojet indices $\mathrm{AL}$ and $\mathrm{AU}$ are available in digital form, (http://swdcdb.kugi.kyoto-u.ac.jp/). The location of the contributing station, however, is not available in digital form so this information was obtained from plots 
provided by the World Data Center C2 for Geomagnetism Data Books of the auroral electrojet indices (AE). Although this was done as carefully as possible, we estimate that the determining station is identified with a time accuracy of approximately $\pm 1 \mathrm{~min}$ corresponding to \pm 1 data point. Thirtyminute intervals were used for the magnetic local time position of the contributing stations. The 12 ground magnetic stations used for the auroral electrojet index (AE) are listed in Table 1 and their locations can be seen in Fig. 1.

Images from the Dynamics Explorer 1 (DE-1) satellite are utilized in this study. The imager on DE- 1 consisted of three individual photometers mounted on the perimeter of the spacecraft and separated by $120^{\circ}$ with one central data control unit (Frank et al., 1981). A two-dimensional image from each photometer was obtain by a combination of the spacecraft rotation around its rotational axis and a "stepping mirror", which was synchronized with the spacecraft rotation by the use of horizon sensors. Of the three photometers two provided images at visible wavelengths while the third provided images at vacuum-ultraviolet wavelengths. Each photometer had a filter wheel equipped with 12 different passband filters at 12 different wavelengths. The response of the photomultiplier could be related to the intensity of the incoming light by the use of the wavelength dependent sensitivity of the sensor itself and the filter used. This study uses data only from the vacuum-ultraviolet photometer.

The criteria used to select the substorm events were:

- Global auroral images should be available at onset and throughout expansion phase;

- "Reasonable" image aspect to the nightside aurora;

- Magnetic storm time events are excluded (as identified from $D_{s t}$ );

- Minimum AL must be less than -200 nT;

- Final AL-AU index must be available.

Based on these criteria we found a total of 34 events occurring between 24 September 1981 and 16 January 1982. The time interval covers from the start of post-launch operations of the imager until aspect for viewing the nightside auroral oval was deteriorating. The minimum AL varied between $-210 \mathrm{nT}$ and $-1550 \mathrm{nT}$, with an average of about $-513 \mathrm{nT}$. The 8-or 12-min image compilation time of the DE-1 images prevented a determination of the onset time based purely on the images. Rather, we chose to combine the image onset with the classical sharp change in slope in the AL trace, to identify a substorm onset sufficiently accurate for this study. Since reliable IMF data were not available for most of the events, the AL trace itself is used for a determination of the start of the growth phase (see, e.g. McPherron, 1970).

\section{Four examples}

Plates 1-4 show images and auroral indices from four substorms which are selected to illustrate the various types of
Table 2. List of events used in the study.

\begin{tabular}{cc}
\hline $\begin{array}{c}\text { Year and Day } \\
\text { Of Year }\end{array}$ & $\begin{array}{c}\text { UT Time of } \\
\text { Minimum AL }\end{array}$ \\
\hline 81267 & $11: 16$ \\
81268 & $16: 12$ \\
81270 & $10: 46$ \\
81275 & $17: 57$ \\
81288 & $8: 15$ \\
81290 & $21: 16$ \\
81292 & $2: 13$ \\
81294 & $15: 10$ \\
81296 & $15: 51$ \\
81296 & $16: 33$ \\
81305 & $3: 45$ \\
81307 & $20: 00$ \\
81308 & $15: 49$ \\
81313 & $11: 31$ \\
81314 & $6: 24$ \\
81314 & $15: 58$ \\
81315 & $13: 12$ \\
81316 & $8: 54$ \\
81318 & $8: 33$ \\
81319 & $3: 50$ \\
81319 & $5: 12$ \\
81323 & $12: 31$ \\
81323 & $18: 23$ \\
81326 & $7: 49$ \\
81326 & $8: 48$ \\
81326 & $9: 05$ \\
81326 & $15: 52$ \\
81332 & $15: 22$ \\
81332 & $21: 57$ \\
81336 & $21: 58$ \\
81353 & $17: 13$ \\
81365 & $8: 45$ \\
82015 & $18: 56$ \\
82016 & $8: 02$ \\
\hline &
\end{tabular}

behavior of the indices. Superposed onto the images are white/black dots indicating the positions of the auroral electrojet (AE) stations with the contributing stations as solid blue dots. Arrows indicate that more than one station contributed to the index during the 12-min exposure and the time stamp indicates the times the shift occurred. A double arrow indicates that the contributing stations alternated during the 12-min image exposure.

\subsection{November 1981: a classical auroral substorm}

Plate 1 shows a fairly small event with AL reaching about $-330 \mathrm{nT}$ and lasting only about $2 \mathrm{~h}$. The AL trace and the emission pattern both exhibit typical bulge type auroral substorm features: the AL trace showing growth phase (11:10-11:25 UT), expansion phase (11:25-11:31 UT) and recovery phase (11:31-12:48 UT); and the images showing a localized, well-defined onset and subsequent poleward 

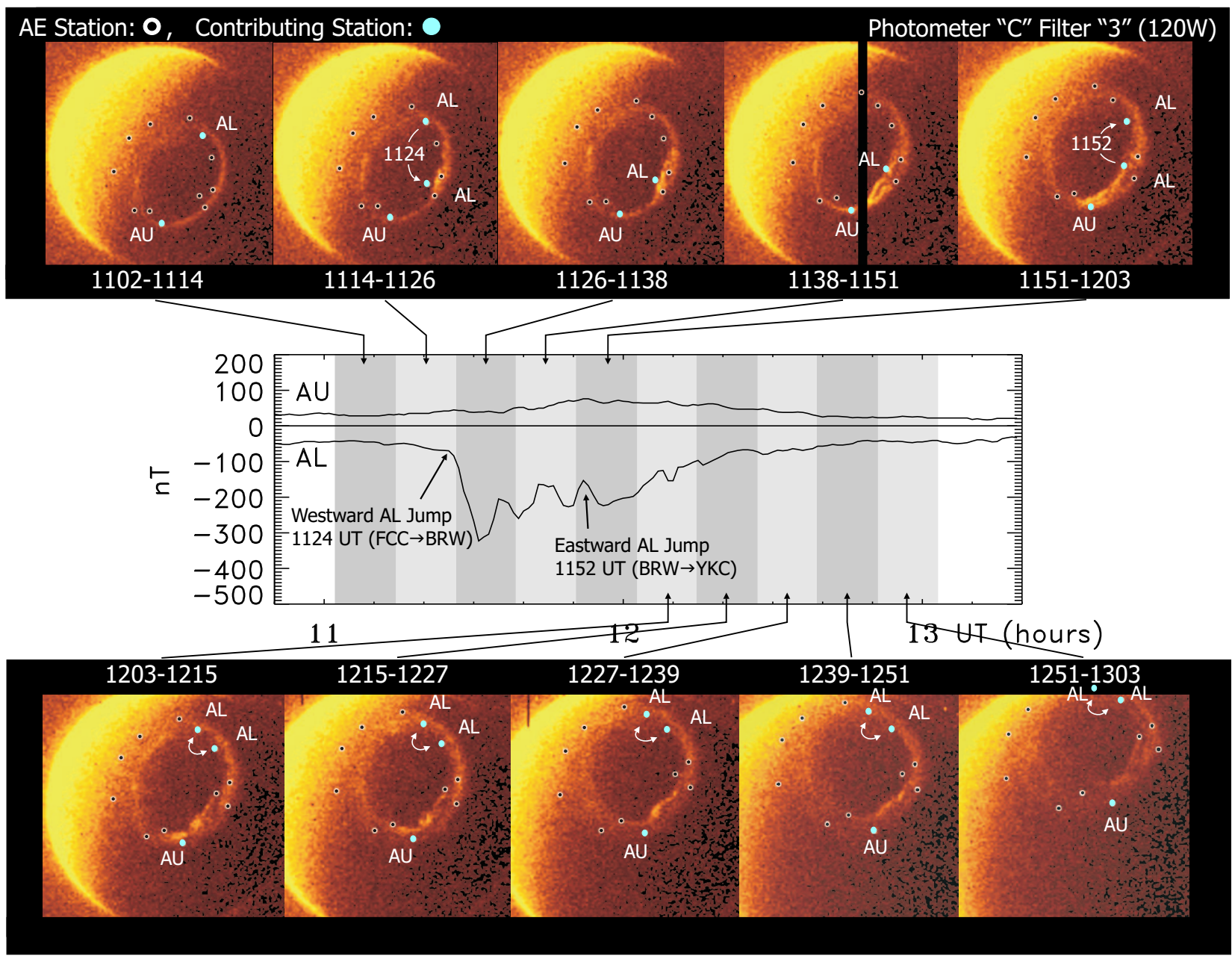

Plate 1. Global auroral images of a classic bulge-type auroral substorm and auroral indices AU and AL from 9 November 1981. Superposed onto images are the $12 \mathrm{AE}$ stations. Single arrows indicate that during the 12-min exposure the contributing station changed from one station to another, while double arrows indicate that the two stations were alternating. The IAGA code for a single station has been added to aid the eye.

expansion as well as a westward traveling surge. During the growth phase the AU index is determined by TIK located at $\sim 19: 30$ MLT while the AL index is determined by FCC located at $\sim 04: 30$ MLT. Hence, both indices are defined by stations located on the flanks. Note that neither of the two $\mathrm{AE}$ stations located right under the oval around midnight magnetic local time (CWE and CMO), nor the three dayside stations located under the illuminated and hence, conductive ionosphere, define either index. At 11:24 UT, the AL trace shows a sudden change in slope, which we interpret as the substorm expansion phase onset. At this time the $\mathrm{AL}$ contributing station jumps from the dawn position to BRW located at $\sim 23: 00$ MLT and slightly poleward of the onset region.

During the expansion phase and early recovery phase $\mathrm{AL}$ stays at BRW. It should be noticed that of the three stations located in the onset region (CMO, BRW, and CWE), AL is determined by the station located in the poleward part of the auroral oval, thereby indicating that in the surge sector the most intense westward electrojet current is found near the high latitude boundary. In the recovery phase, at $\sim 12: 02 \mathrm{UT}$, AL jumps back toward dawn where it stays throughout the rest of the event. While the AL station location exhibits these characteristic jumps the AU does not change station throughout the entire event and hence simply follows the Earth's rotation and ends at $\sim 21: 30$ MLT. Even though the onset occurs several hours east of the AU station the bright emissions travel westward and in the 11:51-12:03 UT image the station is clearly located in the equatorward part of the local time with the brightest emissions. Actually, AU shows a weak maximum during this period.

This classical substorm event indicates that at the substorm onset the AL contributing station makes a jump from a morning sector position to the optical onset location, where it stays throughout the expansion and early recovery phase; in the surge sector the most intense westward electrojet current is 


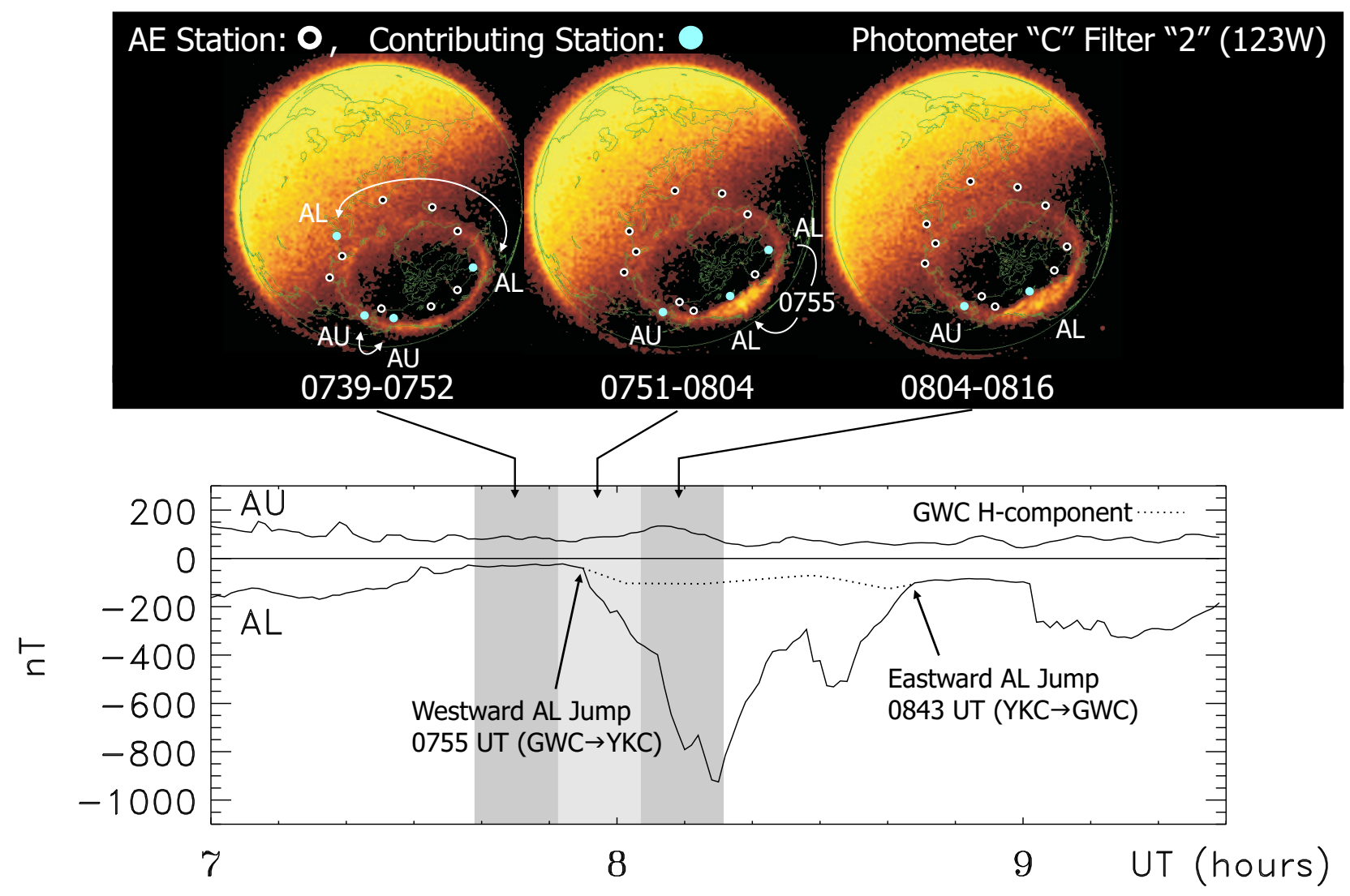

Plate 2. A local event with short or no growth phase occurring 15 October 1981. Same format as for Plate 1. Dotted line indicates the H-component measured at GWC.

found near the poleward boundary; and the eastward electrojet intrudes into the surge local time region but is located near the low-latitude boundary of the UV auroral oval.

\subsection{October 1981: a local event}

Plate 2 shows an event which has a characteristically different behavior than the previous event. The expansion phase, lasts $20 \mathrm{~min}$ (07:55-08:15 UT as identified from AL) and the recovery phase a comparable 28 min (08:15-08:43 UT). Based on AL little or no growth phase is seen prior to the onset which occurred at 07:55 UT, though both GWC (defining AL before and after event) and NAQ (right under oval but weaker than GWC) were located in the dawn hours. Further, the classical slow recovery of the AL index is absent and although the recovery phase lasts 8 min longer than the expansion phase this appears to be due to the secondary intensification at 08:32 UT. Unfortunately, there are no images after 08:04-08:16 UT but the three previous images show a rapid bright poleward expansion around midnight and very little (if any) visible changes on the flanks. At onset the AL defining station jumps from GWC ( 02:30 MLT) to YKC ( 23:00 MLT), which is located slightly poleward of the onset region. Unlike the example shown in Plate 1, the AL stays at YKC throughout the entire event and makes the jump back toward the dawn terminator (GWC 03:30 MLT) at the end of the event at 08:43 UT. The AU contributing station is located at CWE 19:30 MLT until 08:21 UT, when it jumps westward to CCS located near the dusk terminator at $\sim 15: 30$ MLT.

The fact that the AL contributing station jumps back to the same morning sector station (GWC) it was located at before the event enables us to investigate the behavior of the morning sector westward electrojet intensity. While it could be argued that GWC is located slightly poleward of the UV oval it should be noted that NAQ, despite a location right under the UV oval, shows weaker westward electrojet currents overhead than that of GWC. Superposed onto the AL trace is shown the X-direction magnetogram from GWC (dotted line) which was the AL defining station before and after the event. It is interesting that the X-component (which was effectively $\mathrm{H}$ since $|\mathrm{X}|>|\mathrm{Y}|$ ) from this station does not indicate any intensifications of the westward electrojet at that local time. While the AL station located at $\sim 23: 00$ MLT indicates a fairly strong substorm it is not possible to identify any substorm features from the GWC station located at 03:30 MLT. This is further supported by the AU trace showing little or no change during the AL bay. Hence, the intensification of the westward electrojet appears to be entirely confined to the 

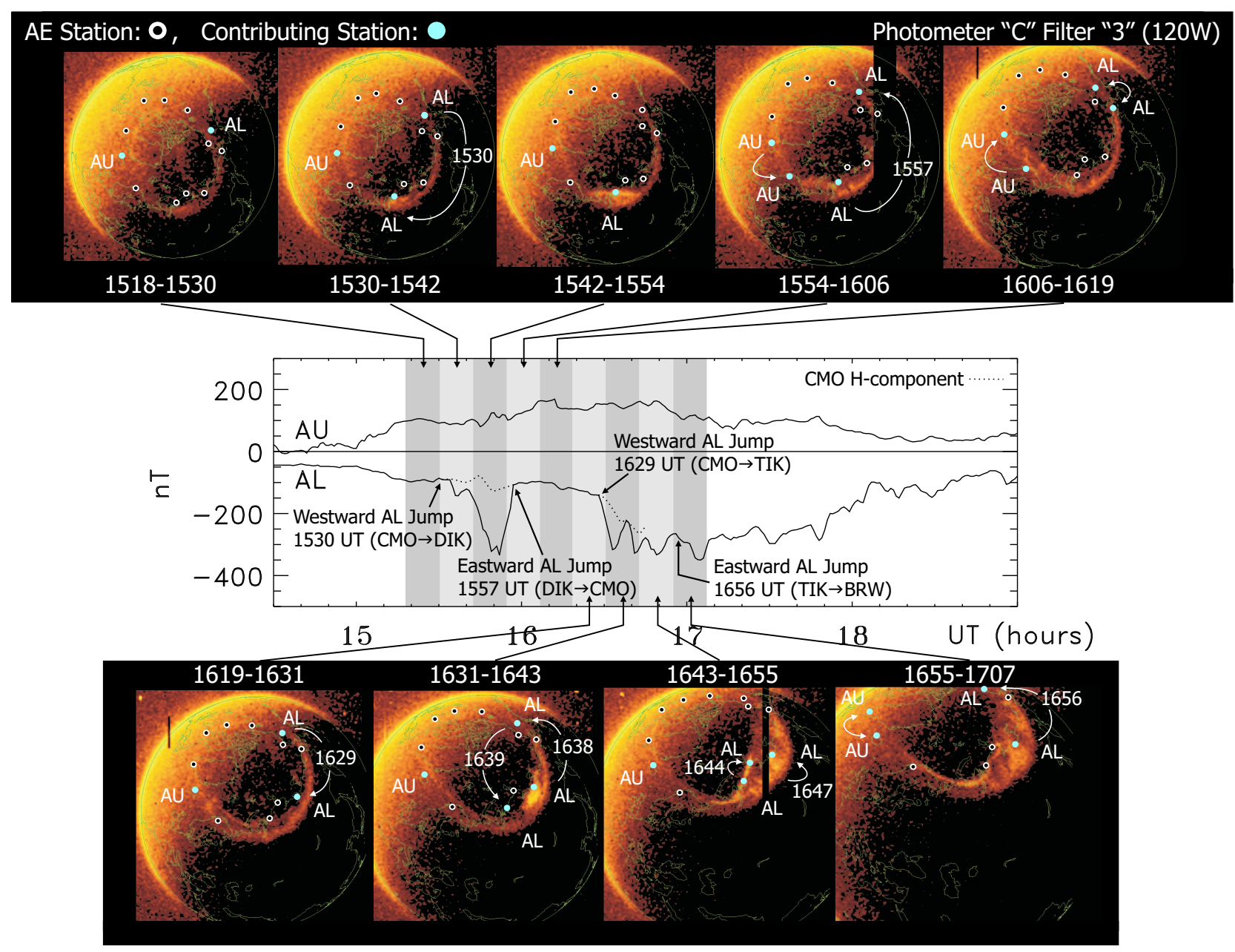

Plate 3. Two consecutive events occurring 23 October 1981. Same format as for Plate 1. Dotted line indicates the H-component measured at CMO.

midnight bulge, while the electrojets on the dusk and dawn flanks are unaffected.

While the two available images indicate that this shortlived event is a classical bulge-type substorm the recovery phase associated AL jump occurs at the end of the event in contrast to the previous example. Further, the electrojets on the flanks show little or no change in intensity, despite the introduction of an intense midnight sector electrojet, indicating that the disturbance is confined to the bulge itself, which is why we refer to it as a local event.

\subsection{October 1981: two consecutive events}

Plate 3 shows a more complex event exhibiting two AL bays. The first short AL bay lasts only 24 min, occurring at 15:3415:58 UT. The images show a well-defined, localized onset at $\sim 22: 00$ MLT, a pronounced subsequent poleward expansion and negligible changes on the flanks. AU is located near the dusk terminator at $\sim 15: 30$ MLT until it makes a jump towards midnight at 15:54 UT. AL makes a jump at 15:30 UT from a location near the dawn terminator $\sim 04: 00$ MLT to
DIK which is located at the poleward edge of the onset region at $\sim 22: 00$ MLT. AL stays at DIK throughout the event until 15:57 UT when it jumps back toward the terminator at $\sim 04: 30$ MLT. The dotted line shows the H-direction magnetogram from the CMO station, which defined the AL trace before and after the event. As in the previous example, there is little or no indication of the event seen in the growth phase magnetogram (CMO). The westward electrojet overhead CMO appears to follow the growth phase pattern that leads to the second onset at 16:29 UT, unaffected by the introduction of the short bay.

Disregarding the short event by following the dotted line in Plate 3 the AL displays a classical substorm trace with a growth phase starting at 15:00 UT, expansion phase onset at 16:29 UT, expansion phase end at 16:33 UT, a broad maximum and a subsequent recovery phase. The images show a very bright onset around midnight MLT with significant subsequent poleward expansion. It should be noted that this second onset and expansion occurs at a later local time than the first. The AL contributing station jumps from $\sim 05: 00$ MLT (CMO) towards midnight at $\sim 00: 30$ MLT (TIK) at 16:29 UT 

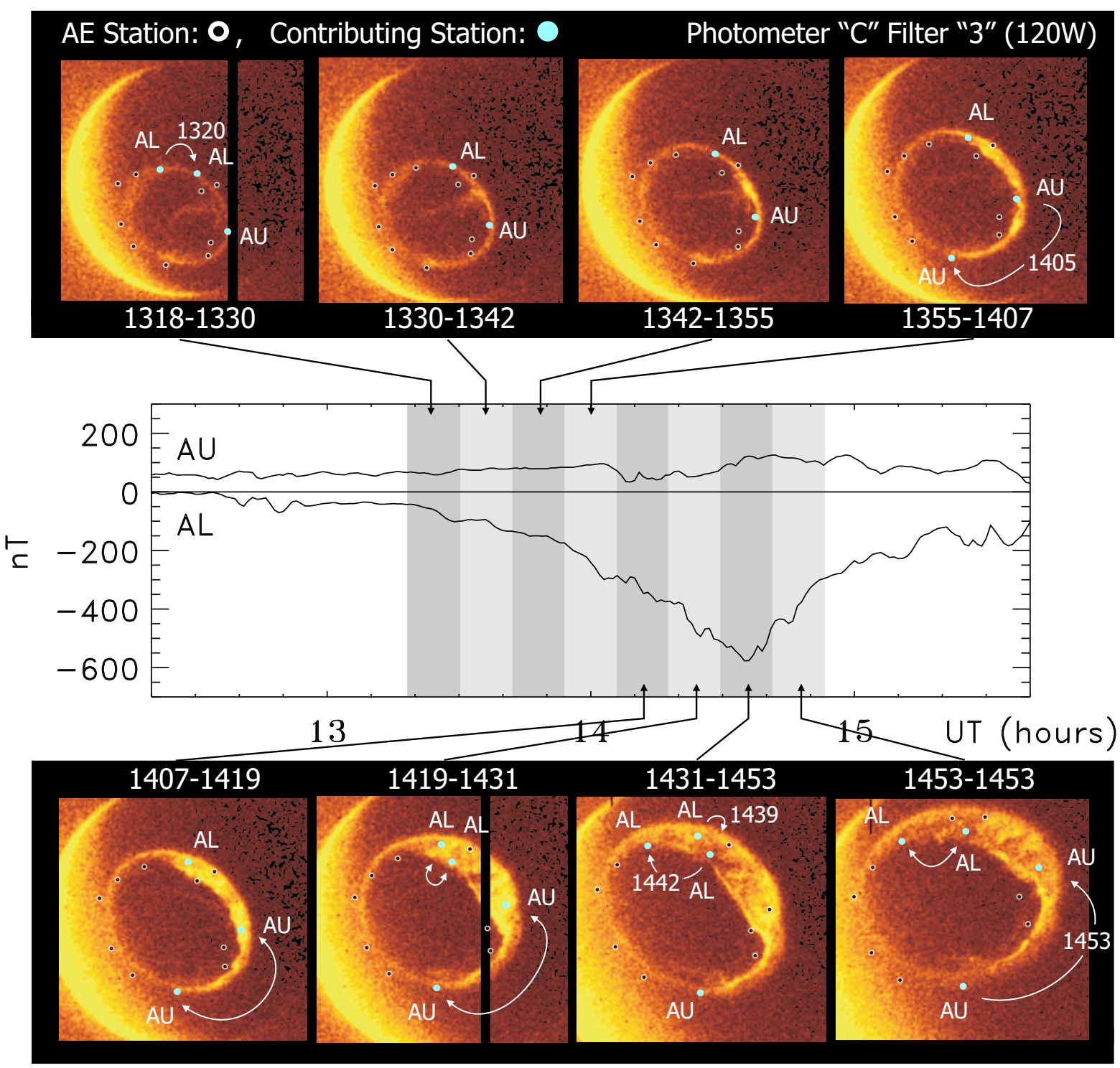

Plate 4. A nonclassical auroral substorm occurring 28 December 1981. Same format as for Plate 1.

exactly when the AL onset is seen. (Note that the portion of the image covering the TIK station would have been acquired before 16:29 UT). The increase in AL seen shortly after the minimum AL is associated with an eastward shift in AL, although the start of the intensification at $~ 16: 39$ UT is again associated with a westward AL jump. AL is located around midnight until $\sim 16: 56$ UT when it jumps back toward the dawn terminator where it stays until the end of the recovery phase. Although AL only spends a single minute at CMO (16:38-16:39 UT), this is important since it indicates that the westward electrojet overhead CMO has been significantly intensified in a 9-min interval following the onset at 16:29 UT. The CMO H-component is indicated as a dotted line until 16:45 UT when the Z-component becomes comparable in size to $\mathrm{H}$. Hence, unlike the first short event and the previous shown in Plate 3, where the flank electrojets re- mained unaffected by the introduction of an intense bulge associated electrojet, this event indicates a more global response. Note also that the jumps at 15:57, 16:29, and 16:39 all bypass two or more stations.

Notice that the reduction in AL at 16:34 UT and subsequent intensification starting at 16:39 UT are also associated with AL jumps from midnight to dawn and back. The two images (bottom center), however, show that this is due to a poleward expansion of the oval that positions DIK and CCS under the oval and consequently, the substorm associated electrojet. So a superposition of the ground stations onto the global auroral images provides a simple explanation of the observed AL trace, since the change in AL and the jumps are due to a change in the spatial configuration of the electrojet which positions the AE station under the electrojet. 


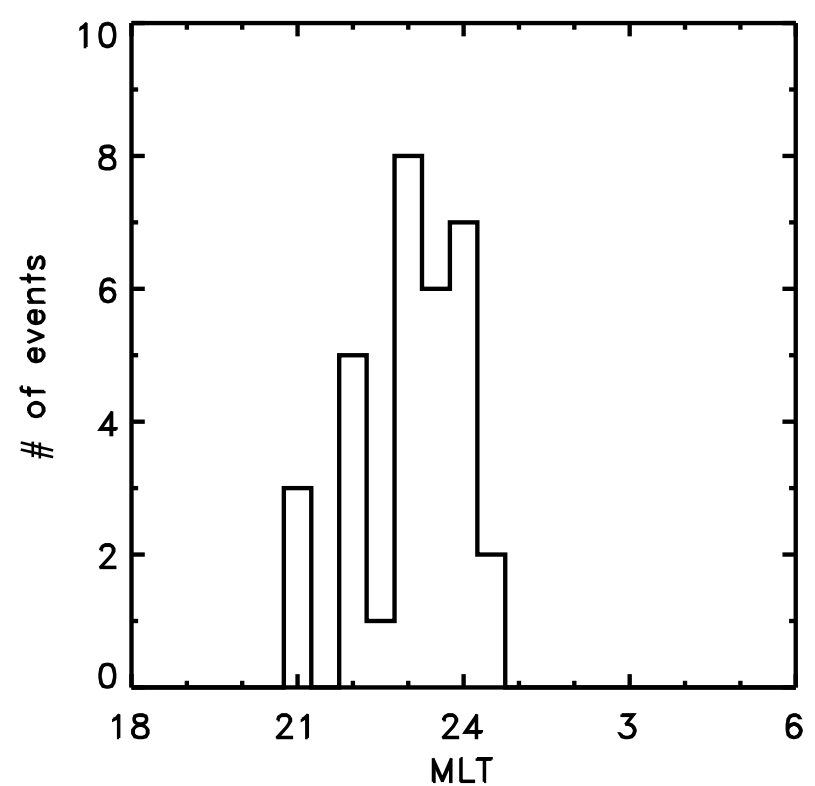

Fig. 2. MLT distribution of substorm onset determined from the global auroral images.

\subsection{December 1981: a nonclassical auroral substorm}

Plate 4 shows a different type of event as identified from the AL trace. During the growth phase a theta arc is seen stretching from midnight across the polar cap toward noon. From the $\mathrm{AL}$ trace no clear onset time is visible but images indicate that it occurs sometime between the 13:42-13:55 UT image and the subsequent 13:55-14:07 UT image. In the latter image two separate brightenings appear at $\sim 21: 00$ MLT and at $\sim 02: 00$ MLT while the theta-arc associated brightening seen in the previous image has faded away. The two separate onsets are each followed by significant poleward expansions, as can be seen in both the 14:19-14:31 UT and 14:31-14:43 images, although the pre-midnight onset appears to become dominant. The AL trace is different from the previous examples since it lacks the typical sharp decrease associated with the onset and since the behavior of the AL contributing station deviates from the previous examples. Prior to the onset the AL station is located at $\sim 02: 00$ MLT and the AU station at $\sim 22: 00$ MLT. During the time of the image onsets the AL station does not change but stays at the same location around 03:00 MLT. Near the maximum and in the recovery phase AL alternates between the dawn stations at $\sim 03: 00$ 06:00 MLT, which both are located near the post-midnight onset. Hence, the characteristic AL jumps (seen in the previous examples) do not take place at either onset or in the recovery phase. Throughout the event the AU station, however, is jumping back and forth between the dusk terminator and the low-latitude part of the intense pre-midnight surge region. In the 14:31-14:43 UT image the station CCS appears to be very close to the poleward boundary of the surge, although it should be noted that in the preceding and the following images the station is located far poleward of the auroral oval.
The magnetogram from this station (not shown) shows that the H-perturbation is negative and minimizes at 14:36 UT (approximately $-260 \mathrm{nT}$ ), while the $\mathrm{Z}$-component is positive and maximizes at 14:36 UT (approximately $+330 \mathrm{nT}$ ). Since $|\mathrm{Z}|$ exceeds $|\mathrm{H}|$ throughout the event, the westward electrojet must have been located well equatorward of the station, which is further elucidated by the images.

This is an example of an event during which the AL jumps do not take place. The event, however, neither displays a classical substorm emission pattern nor has a properly located AE station during the expansion phase. Finally, it should be noted that the AU location indicates the intrusion of the eastward electrojet far into the low-latitude part of the pre-midnight surge, which was also the case in the first example shown in Plate 1.

\section{Data summary}

The examples discussed in Sect. 2 indicate several characteristics of the behavior of auroral electrojet indices, AU and $\mathrm{AL}$. We next investigate the statistical behavior of the AL and AU indices using 34 selected substorms.

\subsection{Westward AL jump at onset}

From the images we were able to determine the onset location for each of the 34 substorms. Figure 2 shows the distribution of the onset location as a function of MLT. We estimate that the onset location is determined with a precision of half an hour MLT but due to the limited temporal resolution of the images the onset can have developed into a broader region rather than a point. In these cases the center of the bright onset region is used. In one case, however, the bright region was so widespread that it was deemed impossible to determine a reliable position and in one case no clear onset location was identifiable. The remaining 32 cases show a distribution shifted to a pre-midnight position, with a typical onset position at 23:00 MLT. Note that 23 of the 32 cases are located pre-midnight while only 2 are slightly postmidnight, with the remaining 7 at midnight. While this is in good agreement with the study by Craven and Frank (1991), the key issue here is that the determination of optical onset location plays an essential role in our study of the AL-AU station behavior and hence for the following analysis.

Three events did not show an AL jump at the time of the AL onset but for the remaining 31 events, Fig. 3a shows the MLT position of the AL station prior to and after the onset associated AL jump, and Fig. 3b shows the MLT change in location from pre-jump to post-jump. The AL position distributions are clearly separated with typical positions at 03:0007:00 MLT before and 22:00-01:00 MLT after, and although we find a large spread in the change, we find that it is always negative, indicating a westward jump. While the average spacing between the AE stations is $2 \mathrm{~h}$ MLT only, three of the 31 events show a jump of $2 \mathrm{~h}$ or less, indicating that the jump typically bypasses stations. Figure $3 \mathrm{c}$ shows the delay 

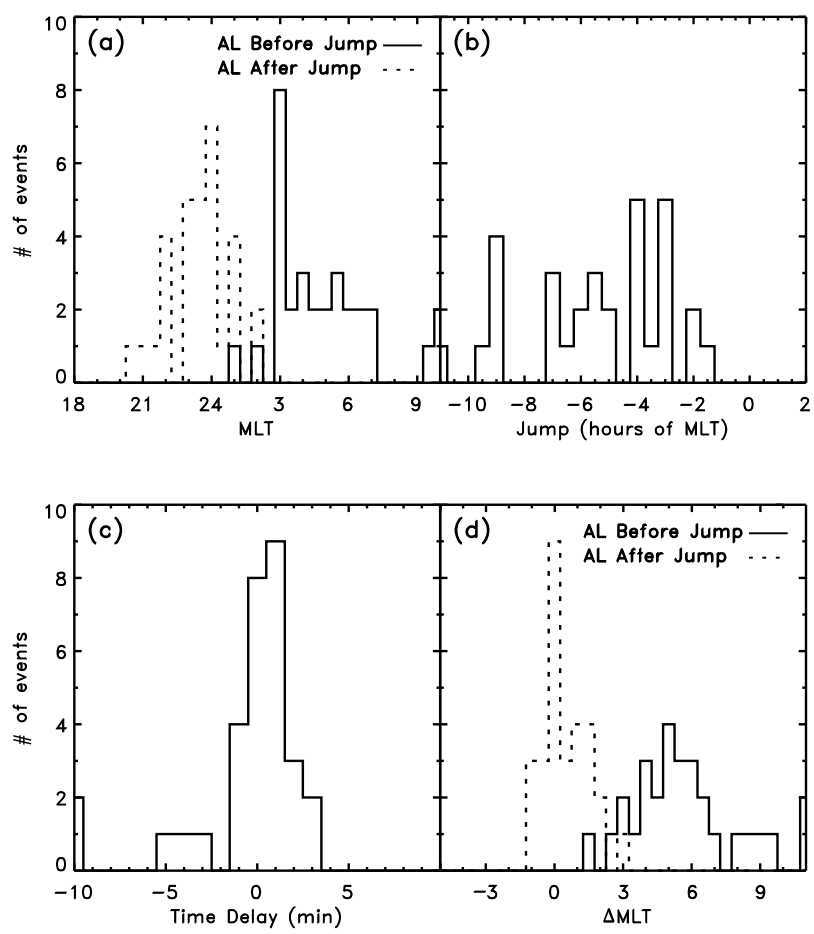

Fig. 3. Panels (a) through (d) are all related to the expansion phase onset associated westward AL jump. Panel (a) shows the distributions of the location of the AL defining station before and after the jump; panel (b) shows the change in location (position after jump, minus position before jump); panel (c) shows the onset time minus the AL jump time; and panel (d) shows the same as (a) but as a function of distance to onset.

between the AL onset and the westward AL jump (using 1min bins). In 21 of the 31 events the jump occurred \pm 1 min of the AL onset, which is within the precision of the data. This simply indicates that the characteristic change in slope of the AL envelope usually occurs at that time and because of the change in the AL contributing station. Of the three events not showing a jump, two had a very poor station location with respect to the onset region, and in one case the $\mathrm{AL}$ contributing station was already located near the onset region before the AL onset. In other words, since the classical drop in the AL trace is associated with a change in station location for over $90 \%$ of the substorms, the AL drop should be considered a spatial as well as a temporal change.

Since the AL station jumps to a location near the substorm onset the spread in the onset location seen in Fig. 2 will obviously result in a smearing of the distribution of the $\mathrm{AL}$ station as a function of MLT. Consequently, plotting the location of the AL contributing station as a function of the MLT distance to the optical onset should reduce this smearing. Figure $3 \mathrm{~d}$ shows the same general pattern as Fig. 3a with two well-separated distributions seen, although the scatter is clearly decreased in the "AL after jump" distribution. This distribution also shows the difference between the AL position after the jump and the onset location determined from the images. While the typical location after the contributing
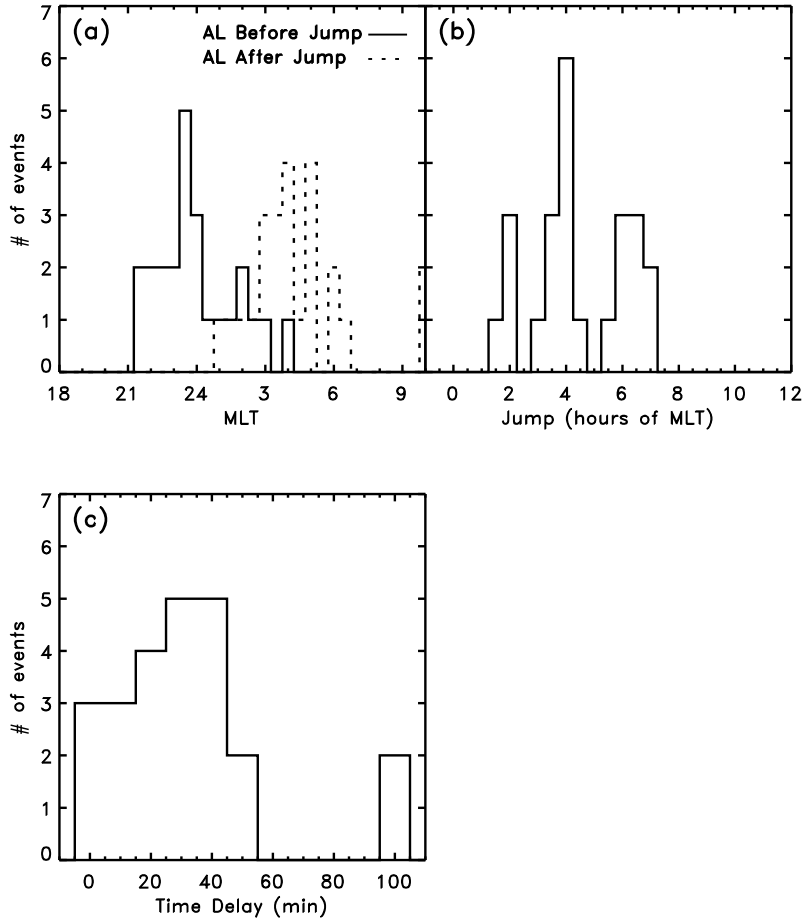

Fig. 4. Panels (a) through (c) are all related to the eastward AL jump during the substorm recovery phase. Panel (a) shows the distributions of the location of the AL defining station before and after the jump; panel (b) shows the change in location (position after jump minus position before jump); panel (c) shows time of the AL jump minus time of end of expansion phase.

station jump is $0 \triangle \mathrm{MLT}$ hours, it should be noted that the distribution is skewed toward later hours, indicating that the maximum electrojet intensity typically is found at or just east of the optical onset.

\subsection{Eastward AL jump in the recovery phase}

The three events shown in Plates 1-3 all show an eastward jump of the AL contributing station during the recovery phase. Figure 4a shows the position of the AL contributing station before and after the jump and Fig. $4 \mathrm{~b}$ shows the number of hours of MLT the AL station jumps. From the examples it is not clear exactly when in the substorm time frame this eastward jump takes place. Figure $4 \mathrm{c}$ shows the delay between the eastward jump and the end of the expansion phase (in 10-min bins). Notice that when comparing Figs. $3 \mathrm{c}$ and $4 \mathrm{c}$ the time scale has been changed considerably, indicating no systematic behavior in the return to the pre-dawn hours, but rather that the jump takes place sometime after the end of the expansion phase. When comparing the location of the AL station before the westward AL jump and after the eastward AL jump we find that, on average, the AL station is located $\sim 1 \mathrm{~h}$ MLT closer to midnight after the jumps. 

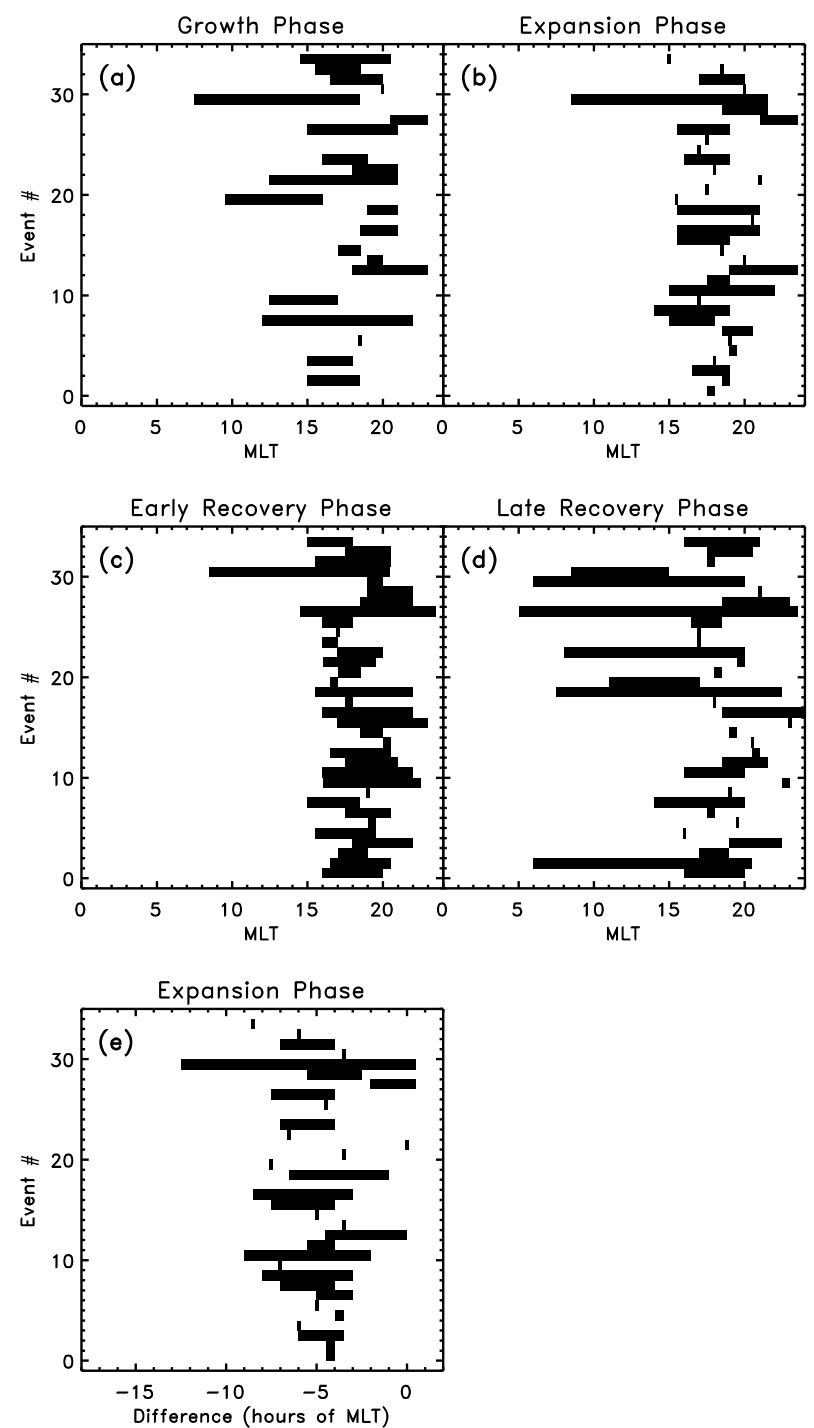

Fig. 5. Panels (a) through (e) are all related to the AU station location. Black horizontal bars indicate the MLT interval in which the AU defining station was located in the particular phase. Early and late recovery phases are defined as the first $2 / 3$ of the recovery phase and the last $1 / 3$, respectively. Panel (e) shows the difference between the AU station and the visible onset location (positive is toward east).

\subsection{AU behavior}

Unlike the observations of the AL contributing station the AU station location does not show any changes associated with the onset. We found no indications of jumps or other systematic behavior. Figure 5 shows the position of the AU station during growth phase, expansion phase, early recovery phase (defined as the first $2 / 3$ time of the recovery phase), and late recovery phase (defined as the last $1 / 3$ time of the recovery phase). The black horizontal bars indicate in which MLT interval the AU defining stations were located during the particular phase. Although the definition of the late and early recovery phase is somewhat arbitrary, we find that the spread in the position of the AU contributing station decreases by the use of this definition (Figs. 5c-d). Of the 34 events only 21 displayed a growth phase as identified from AL and for these 21 events the spread in the position of the AU contributing station is clearly considerable. During the expansion phase and early recovery phase the AU location distribution narrows and is typically located in the 15:00-23:00 MLT interval, while the spread in the late recovery phase is striking. Figure 5e shows the position of the AU station during the expansion phase with respect to the location of the onset. As expected the $\mathrm{AU}$ is determined by stations located west of the onset region $(\triangle \mathrm{MLT}<0)$ but it should be noted that in 4 events the AU contributing station is located (for a time) at approximately the same local time as the onset. This indicates an intrusion of the eastward electrojet far into the substorm surge local time interval, although it is important to note that in all four cases we found the AU station to be positioned in the equatorward part of the oval.

\section{Discussion}

With an understanding of where the AL contributing station jumps with respect to the morphology of the optical substorm and when these jumps takes place with respect to the substorm time scale, we can gain an understanding of station location behavior. We will base the interpretation of our observations on the concepts developed primarily by Kamide and co-workers, as well as our empirical ionospheric electrodynamic substorm model.

Kamide and Kokubun (1996) suggested that the westward ionospheric electrojet system consists of two components: the convection component and the substorm current wedge component. While the former represents large-scale magnetospheric plasma convection controlled by solar windmagnetosphere interactions, such as the dayside merging, the latter is associated with the unloading of energy stored in the tail. They hypothesized that the convection electrojet is enhanced at the initiation of the growth phase, while the onset of the three-dimensional substorm current wedge introduces the substorm expansion phase, with the ionospheric part producing the classical sharp drop in the AL trace. They concluded that the two-cell convection pattern produces the eastward electrojet that is monitored by the AU index and the early morning convection part of the westward electrojet monitored by AL before the jump. Upon the introduction of the substorm current wedge, the AL index station then moves to the dark sector. They emphasize that the two components of the westward electrojet are contiguous in terms of the ionospheric current. Similarly, Baumjohann (1983) suggested that the current resulting from the substorm current wedge can intrude deeply into the evening sector along with the westward traveling surge. He considered the latter electrojet to be superimposed on the convection electrojet. In the following discussion we adopt the Kamide and Kokubun (1996) terminology of the two components of the 
westward electrojet but wish to point out that our analysis does not address the topic of their causes.

Based on observations from the Dynamics Explorer spacecraft, Gjerloev and Hoffman (2000a, b, 2001, 2002) developed an empirical self-consistent model of the electrodynamics in bulge-type auroral substorms during the expansion phase through early recovery phase. They produced models of the height integrated Hall and Pedersen conductivity using measurements of electron precipitation, a convection electric field model from electric field and ionospheric convection measurements, and from these models they calculated the horizontal ionospheric currents and the field-aligned currents. Figure 6 shows their model of the total ionospheric height integrated horizontal current $\left(\overline{\mathrm{I}}_{\text {tot }}=\overline{\mathrm{I}}_{\text {Pedersen }}+\overline{\mathrm{I}}_{\text {Hall }}\right)$. The westward electrojet appears to consist of a wide postmidnight component and an intense narrow pre-midnight component at latitudes above the Harang region (see Gjerloev and Hoffman, 2002). The two components are connected across midnight, although the electrojet intensity displays a characteristic local minimum around midnight. They interpreted their results as a confirmation of the two component westward electrojet concept. This framework enables us to interpret our observations of the AL and AU station behavior in terms of the overhead electrojets.

The westward and eastward jumps of the AL defining station indicate that the center of the westward electrojet does not move continuously from the dawn sector to the onset region and back to the dawn sector. Typically, the AL defining station jumps across several stations, indicating that the change is not due to a modification of the pre-onset electrojet system but rather to the introduction and disappearance of a substorm bulge associated electrojet. The clear separation of the two distributions seen in Figs. 3a and 4a show that the maximum intensities of the two systems are separated in local time and hence a local minimum in the electrojet intensity is likely to be separating them. Based on the current study we are not able to determine whether the two electrojet components are completely separated (local minimum is zero) or if some current is flowing from the convection electrojet into the wedge electrojet (local minimum is greater than zero but smaller than both electrojet maxima). It is, however, in good agreement with the Gjerloev and Hoffman (2002) model which clearly shows a local minimum around 23:00-24:00 MLT. They found that much of the wide post-midnight convection electrojet closed to the magnetosphere through field-aligned currents in the lower part of the substorm bulge region as it approached midnight. The wedge electrojet is located at latitudes above the Harang region in the pre-midnight region. In the 21:00-23:00 MLT region it is fed by an imbalance between the region 1 FAC and the narrow but intense region 0 FAC (see Hoffman et al., 1994, for an extensive discussion of this important FAC region) under which the electrojet flows. At earlier local times (typically 19:00-21:00 MLT) it is drained by an imbalance between these currents overhead FAC sheets (see Fig. 7). Thus, based on the two-component electrojet concept and the Gjerloev and Hoffman empirical model the jumps in the AL

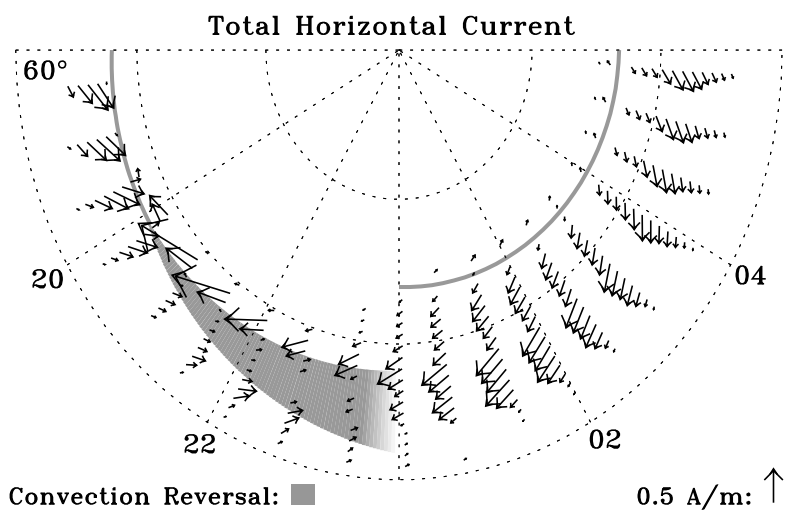

Fig. 6. Total height integrated horizontal currents during the expansion phase through early recovery phase (wedge phase) of a classical auroral substorm from the empirical model of Gjerloev and Hoffman (2002). The shaded area indicates the Harang region which during substorms is a region of weak meridional electric field.

contributing station can be explained as being due to the introduction of a new electrojet system located pre-midnight which is more intense that the convection electrojet located post-midnight. When this short-lived, intense wedge component weakens the AL contributing station shifts back to a position under the weaker but long-lived convection electrojet. Since there is no eastward electrojet component introduced at the substorm expansion phase the location of the AU contributing station does not display any similar behavior.

The eastward recovery phase jump was investigated by Kamide (1988). He found that in $57 \%$ of the substorms the AL defining station made an eastward shift from the 15:0003:00 MLT sector (during peak $\mathrm{AL} \pm 15 \mathrm{~min}$ ) to the morning sector 03:00-09:00 MLT (after AL peak $+15 \mathrm{~min}$ ). Using the same definition we find that 18 events show an eastward jump of $15 \mathrm{~min}$ or more after the end of the expansion phase, which corresponds to $53 \%$ of our events, in agreement with his results. An interesting study covering a full day was published by Allen and Kroehl (1975), in which they identified the most frequent $\mathrm{AL}$ and $\mathrm{AU}$ contributing station for each hour of UT (see their Fig. 3, p. 3670). It is interesting to see that despite the use of these average hourly locations three of five substorms occurring that day showed the AL jumps described in this paper. They referred to these simply as exceptions to the average 03:00-06:00 MLT AL station location. Note that our analysis provide much narrower local time intervals where the AL defining station exists, than these earlier studies.

In discussing Plates 1 and 3 it was noted that during the expansion phase the AL defining station was located near the poleward edge of the surge despite two other stations being located in the center of the bulge. Consistently, we found this to be the case. This implies that the intense wedge electrojet maximizes near the poleward edge rather than in the center of the surge, which is in good agreement with the intense narrow wedge current located poleward of the Harang region (see Fig. 6). The western extension of this wedge current 

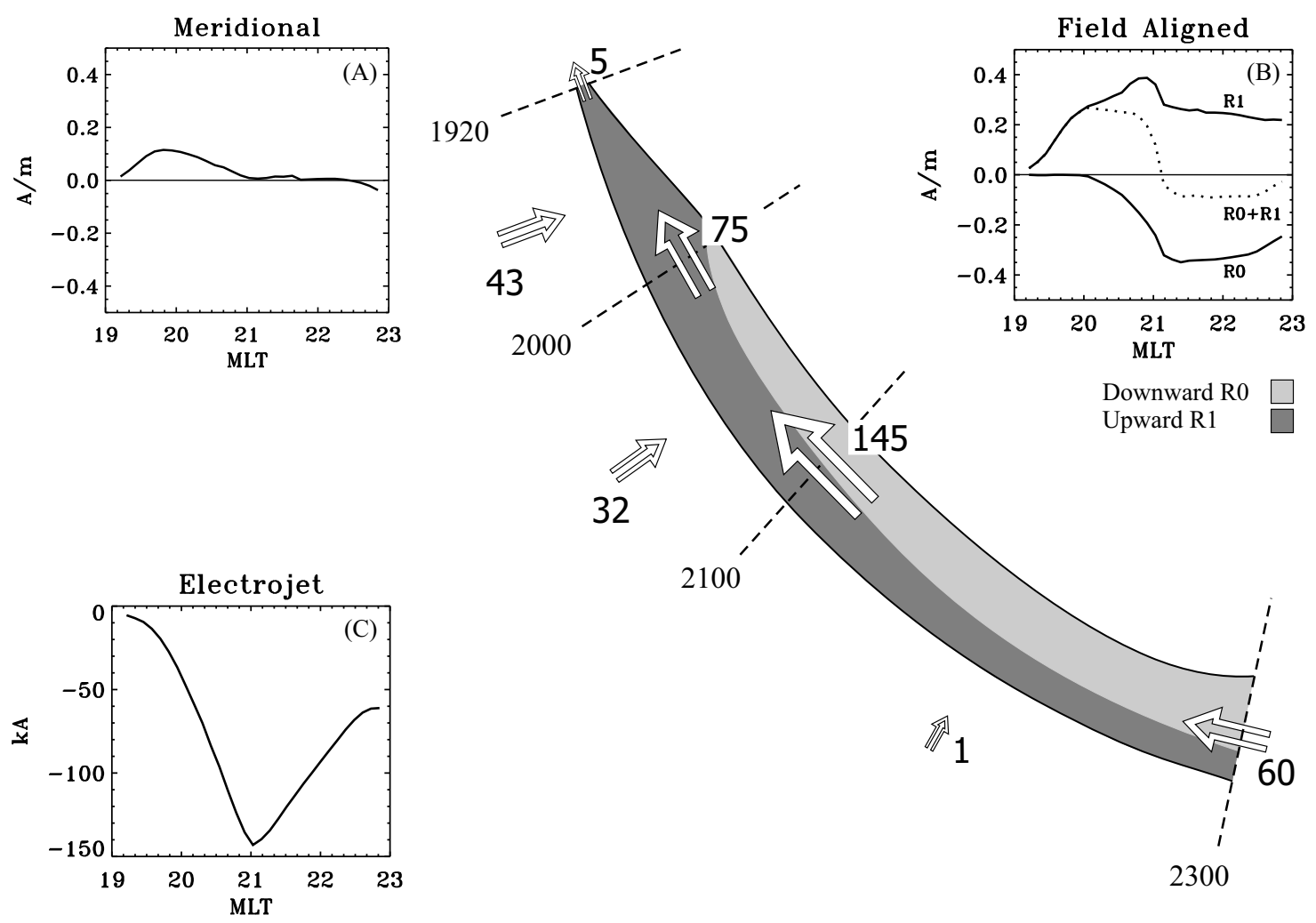

Fig. 7. An illustration of the ionospheric part of the substorm current wedge from Gjerloev and Hoffman (2002). Numbers are in kA and arrows indicate direction of horizontal current direction. Although the arrow size implies strength of current they are not to be scaled. The arrows outside the wedge itself indicate the meridional current contribution to the wedge system. The two top panels show the meridional current intensity along the low-latitude boundary of the wedge and the field-aligned current intensity within the wedge. Finally, the bottom left panel shows the total wedge electrojet strength as a function of MLT.

was addressed in Sect. 4.1, where we found that during the expansion phase and early recovery phase the distribution of the AL station location with respect to the onset location (Fig. 3d) is skewed toward the east (MLT hours later than average onset at $23 \mathrm{MLT}$ ). This implies that the westward wedge electrojet extends toward the east and that the optical onset indicates the termination of the westward flowing wedge electrojet. Hence, intense upward field-aligned currents are expected in or near the onset region (later the head of the surge) responsible for the drainage of the electrojet, in good agreement with observations of energetic electron precipitation (e.g. Fujii et al., 1994) and net FACs (e.g. Hoffman et al., 1994).

According to the two-component electrojet concept, the introduction of the three-dimensional substorm current wedge results in an intense ionospheric westward electrojet component and hence, it is expected that the relative strength of the eastward (AU) and westward (AL) electrojets show a pronounced substorm phase dependence. The phase dependent AU-AL relationship is investigated in Fig. 8. The linear fit is weighted by the number of points entered from each event, in order to remove any bias toward single events. The early and late recovery phases are separated by the east- ward recovery phase AL jump. Although the scatter of points is considerable, it is worth noting that the slope is close to 1 during the growth phase, while the westward convection electrojet appears to be about twice as strong as the eastward electrojet in the late recovery phase, likely due to dawnside conductivity enhancements caused by the precipitation of eastward drifting electrons. These results are in good agreement with the study by Kamide and Kroehl (1994), who found that during isolated substorms the maximum $|\mathrm{H}|$ perturbation around 18 MLT was $1 / 3$ of the maximum $|\mathrm{H}|$ perturbation around $00 \mathrm{MLT}$ and $1 / 2$ of the maximum $|\mathrm{H}|$ perturbation around $06 \mathrm{MLT}$. It should, however, be noted that simply comparing maximum values at a specific local time will result in a comparison of electrojet intensities at different phases of the substorm and hence some caution is needed when comparing to the present study.

Davis and Sugiura (1966) found that the AL(7) was typically determined by stations located at $\sim$ 03:00 MLT, which was later confirmed by Allen and Kroehl (1975), who also found during disturbed times (AL $\leq-50 \mathrm{nT})$ that the $\mathrm{AL}(11)$ station was typically located at $\sim 03: 00$ MLT. It is, however, important to keep in mind that the AL index is not defined by the maximum electrojet intensity but solely by the maximum 


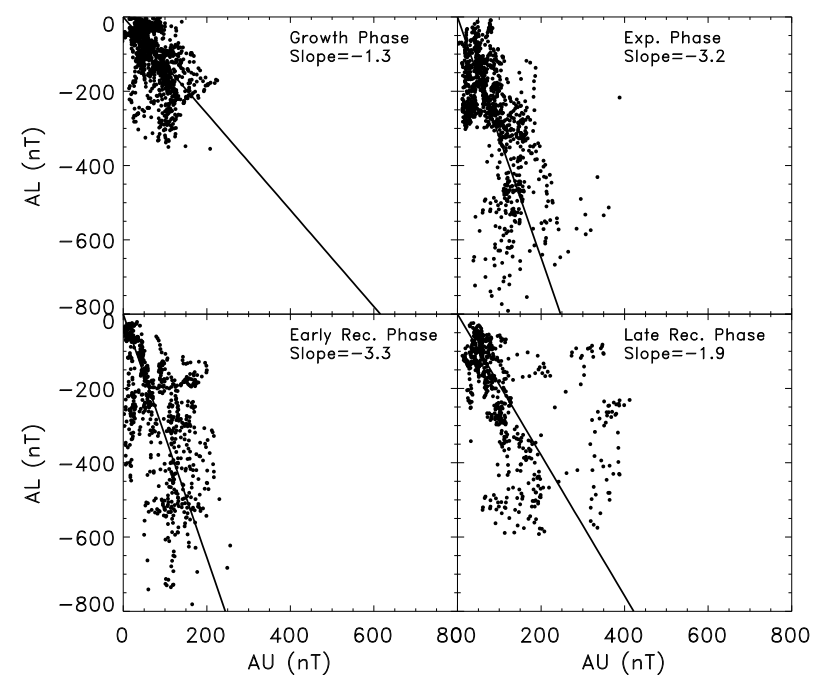

Fig. 8. $\mathrm{AU}$ shown as a function of $\mathrm{AL}$ for the 34 passes. Early and late recovery phases are defined by the eastward AL jump from onset region to dawn region. Linear fits are weighted by the number of points supplied by each event in order to avoid any bias toward single events.

in the electrojet intensity observed at the positions of the selected AE stations. When comparing our results with these previous studies four factors should be pointed out: 1) we find that the wedge phase during which the AL station might be located in the surge lasts $\sim 50 \mathrm{~min}$, which is only about $1 / 3$ of the entire average substorm; 2) the Gjerloev and Hoffman model indicates that the post-midnight electrojet occupies a much larger area than the pre-midnight wedge, giving a higher probability that an $\mathrm{AE}$ station will be located near the maximum in the convection electrojet compared with the wedge electrojet; 3) we used AL(12) while Davis and Sugiura used AL(7) and Allen and Kroehl used AL(11) (where the number indicates the number of stations used to deduce the AL index) and consequently, our AL was deduced from an improved spatial coverage; and 4) Davis and Sugiura used all data while Allen and Kroehl simply used $\mathrm{AL} \leq-50 \mathrm{nT}$ as selection criteria. All these four factors will skew a statistical average location of the AL station toward the morning side, and hence it is no surprise that the convection electrojet, on average, defines the AL station position. It should, however, be noted that a careful examination of the results by Davis and Sugiura (see their Fig. 9) shows a second peak at midnight MLT in the distribution of the AL station location as a function of MLT, which can be explained by our findings. Also, in the study by Allen and Kroehl two stations show a weak secondary peak located pre-midnight (FCC and CCS) while the rest have a tail stretching into the pre-midnight sector.

Figure 9 provides a schematic summary illustration of our observations using generic substorm traces of the $\mathrm{AL}$ and AU (inspired by Fig. 13, p. 13041 in Kamide and Kokubun, 1996). The dotted and dashed lines indicate the intensity of

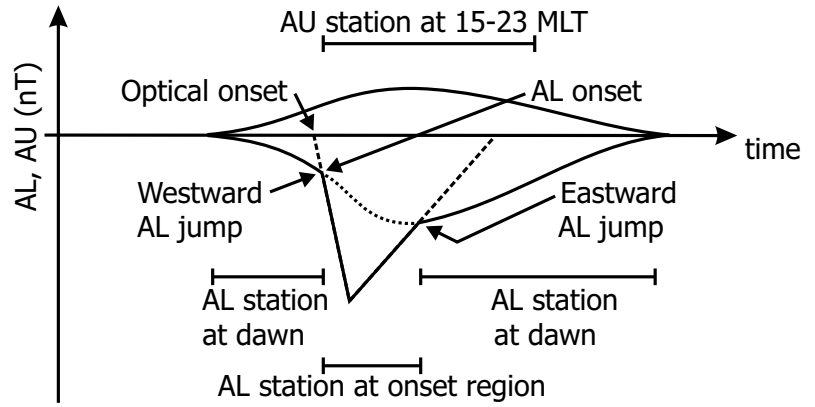

Fig. 9. Illustration showing the typical behavior of the auroral electrojet indices AL and AU (inspired by Fig. 13, p. 13041 in Kamide and Kokubun, 1996). The two components of the westward electrojet (wedge and convection) are indicated. The AL station is located at the onset region during the wedge phase (expansion and early recovery phase).

the convection and wedge components, respectively, when these are not defining the AL. According to the figure and the two component westward electrojet concept, the wedge electrojet dominates during the expansion phase through early recovery phase, which, therefore, could be referred to as the wedge phase. The figure further indicates that the AL onset is delayed from the optical onset, since the introduction of the substorm current wedge is associated with the optical onset. The length of this delay, however, will strongly depend on the location of the ground magnetometer station relative to the onset. Assuming that a station is located right under the optical onset the delay is likely on the order of a few minutes but if an expansion of the oval is needed to place the station under the electrojet (as Plate 4 illustrates) longer delays are expected. In the event shown in Plate 2 and the first event in Plate 3 the westward convection electrojet showed little or no change associated with the introduction of the substorm current wedge, while, on the other hand, the second event in Plate 3 indicated that the convection electrojet intensified shortly after the expansion phase onset. These observations do not show any consistent response of the convection electrojet to the introduction of the wedge electrojet and hence, our observations indicate the two westward electrojet components to be quasi-independent. Consequently, the entire auroral electrojet system could be referred to as the threecomponent auroral electrojet system.

\section{Summary and conclusions}

This study investigated the behavior of the auroral electrojet indices AU and AL by the use of global auroral images. The 12 AE stations were superposed onto global auroral images and the $\mathrm{AL}$ and $\mathrm{AU}$ contributing stations were identified. This enabled an understanding of the temporal as well as spatial behavior of the indices with respect to the substorm coordinate system and timeframe. Based on this simple technique we have concluded that: 
1. At the onset of the substorm expansion phase the AL contributing station makes a characteristic jump from a location near the dawn terminator to the optical onset region;

2. During the expansion phase and early recovery phase, the AL contributing station is located near the poleward edge of the surge region, and during the recovery phase, the AL contributing station makes a characteristic jump from the optical onset region back to the post-midnight region;

3. The AU contributing station location shows considerable scatter during the growth phase with a preferred location in the 12-23 MLT region, less scatter in the expansion through early recovery phase with a preferred location in the 15-23 MLT region, and is finally scattered throughout the 6-24 MLT sector in the late recovery phase;

4. During the growth phase the $|\mathrm{AL}|$ and $|\mathrm{AU}|$ are of comparable strength, during expansion phase and early recovery phase the $|\mathrm{AL}|$ is about three times stronger than the $|\mathrm{AU}|$, and finally, the $|\mathrm{AL}|$ is about twice $|\mathrm{AU}|$ during the late recovery phase.

We further find that the onset associated AL jump typically bypasses stations, resulting in well separated distributions of the AL contributing station before and after the westward AL station jump. This further indicates that the change is due to the introduction and disappearance of a substorm bulge associated electrojet component rather than a reconfiguration of the pre-onset electrojet system. At expansion phase onset the change in the slope of the AL envelope usually occurs at the time of the change in the AL station location and hence, should be viewed as a spatial as well as a temporal variation. The two-component westward electrojet concept of Kamide and Kokubun (1996) and the empirical self-consistent substorm model of the three-dimensional current system by Gjerloev and Hoffman (2000a, b, 2001, 2002) enable us to understand our observations in terms of the auroral electrojet morphology. The convection electrojet closes to the magnetosphere as it approaches midnight in the bulge region, while the wedge electrojet is fed pre-midnight by an imbalance of Region 0 and Region 1 field-aligned currents at latitudes above the Harang region. This results in a possible local minimum in the total electrojet current (integrated in latitude and altitude) near midnight. This concept, however, also indicates that the classical AL envelope onset is slightly delayed from the optical onset. We further find that during the expansion phase and early recovery phase the $\mathrm{AL}$ defining station is typically located near the poleward edge of the surge, thereby indicating the maximum wedge electrojet position. This is the location of the intense substorm current wedge electrojet in the Gjerloev and Hoffman model. Finally, we found that the dawn side westward electrojet can be unaffected by the introduction of the substorm bulge associated westward electrojet (wedge), thereby indicating the quasi-independence of the two electrojet components.
Acknowledgements. The authors would like to thank M. R. Dvorsky for her outstanding support with the global auroral images. The authors further wish to acknowledge Kyoto World Data Center for $\mathrm{AE}$ data and quick look $\mathrm{AE}$; the Danish Meteorological Institute, PI J. Watermann for ground magnetometer data; CANOPUS, Canadian Space Agency, PI J. Sampson for ground magnetometer data; GIMA, UAF Geophysical Institute, PI J. Olson for ground magnetometer data; and finally SPIDR for ground magnetometer data. Also thanks to D. S. Taguchi and D. Vassiliadis for valuable comments. This study was performed while JWG held a National Research Council Postdoctoral research position at NASA-Goddard Space Flight Center.

Topical Editor T. Pulkkinen thanks two referees for their help in evaluating this paper.

\section{References}

Ahn, B.-H., Kroehl, H. W., Kamide, Y., and Kihn, E. A.: Universal time variations of the auroral electrojet indices, J. Geophys. Res., 105, 267-275, 2000.

Ahn, B.-H., Moon, G.-H., Sun, W., Akasofu, S.-I., Chen, G. X., and Park, Y. D.: Universal time variation of the $D_{s t}$ index and the relationship between the cumulative $\mathrm{AL}$ and $D_{s t}$ indices during geomagnetic storms, J. Geophys. Res., 107, doi:10.1029/2002JA009257, 2002.

Allen, J. H. and Kroehl, H. W.: Spatial and temporal distributions of magnetic effects of auroral electrojets as derived from AE indices, J. Geophys. Res., 80, 3667, 1975.

Baumjohann, W.: Ionospheric and field-aligned current systems in the auroral zone: A concise review, Adv. Space. Res., 2, 55-62, 1983.

Craven, J. D. and Frank, L. A.: Diagnostics of auroral dynamics using global auroral imaging with emphasis on large-scale evolutions, Auroral Physics, edited by Meng, C.-I., Rycroft, M. J., and Frank, L. A., 273, Cambridge University Press, Cambridge, 1991.

Davis, T. N. and Sugiura, M.: Auroral electrojet activity index AE and its universal time variations, J. Geophys. Res., 71, 785, 1966

Frank, L. A., Craven, J. D., Ackerson, K. L., English, M. R., Eather, R. H., and Carovillano, R. L.: Global auroral imaging instrumentation for the Dynamics Explorer mission, Space. Sci. Instrum., 5, 369-393, 1981

Fujii, R., Hoffman, R. A., Anderson, P. C., Craven, J. D., Sugiura, M., Frank, L. A., and Maynard, N.: Electrodynamic parameters in the nighttime sector during auroral substorms, J. Geophys. Res., 99, 6093-6112, 1994.

Gjerloev, J. W. and Hoffman, R. A.: Height-integrated conductivity in auroral substorms, 1. Data, J. Geophys. Res., 105, 215, 2000a

Gjerloev, J. W. and Hoffman, R. A.: Height-integrated conductivity in auroral substorms, 2. Modeling, J. Geophys. Res., 105, 227 , $2000 \mathrm{~b}$.

Gjerloev, J. W. and Hoffman, R. A.: The convection electric field in auroral substorms, J. Geophys. Res., 106, 12919, 2001.

Gjerloev, J. W. and Hoffman, R. A.: Currents in auroral substorms, J. Geophys. Res., 107, A8, doi:10.1029/2001JA000194, 2002.

Hoffman, R. A., Fujii, R., and Sugiura, M.: Characteristics of the field-aligned current system in the nighttime sector during auroral substorms, J. Geophys. Res., 99, 21 303, 1994.

Kamide, Y.: The two-component auroral electrojet, Geophys. Res. Lett., 9, 1175-1178, 1982. 
J. W. Gjerloev et al.: Substorm behavior of the auroral electrojet indices

Kamide, Y.: Electrodynamic processes in the Earth's ionosphere and magnetosphere, Kyoto Sangyo University Press, Kyoto, Japan, 1988.

Kamide, Y. and Kroehl, H. W.: Auroral electrojet activity during isolated substorms at different local times: A statistical study, Geophys. Res. Lett., 21, 389-392, 1994.
Kamide, Y. and Kokubun, S.: Two-component auroral electrojet: Importance for substorm studies, J. Geophys. Res., 101, 13027 , 1996.

McPherron, R. L.: Growth phase of magnetospheric substorms, J. Geophys. Res., 75, 5592, 1970.

Rostoker, G.: Geomagnetic indices, Rev. Geophys. Space Phys., 10, 935, 1972 